\title{
An Overview of Information Tools and Technologies for Competitive Intelligence Building: Theoretical Approach
}

\author{
Celina M. Olszak \\ University of Economics, Katowice, Poland \\ celina.olszak@ue.katowice.pl
}

\begin{abstract}
The paper refers to the Competitive Intelligence (CI) that is an important area of study for both practitioners and researches. CI is a subset of Business Intelligence (BI), providing balanced picture of the environment to the decision makers. It concerns the collecting and analyzing of the information about the behaviors of the various markets' actors in order to make certain decisions based on market trends. This type of information is mainly semi-structured or unstructured nature- in contrast to the well-structured information used in BI. It turns out that many previous information tools used to build BI are insufficient and adequate for CI.

The research study is mainly exploratory and descriptive in nature, with the objective of providing an overview of the issue of CI and investigating the various information tools and technologies for CI building.

The structure of this paper is organized as follows. Firstly, the idea of CI is explained and the most important differences between BI and CI are highlighted. Next, the most significant information tools and technologies for building CI are preceded. Finally, some guidelines and recommendations are provided in order to build CI in organizations. Some limitations of this research are indicated as well. What is more, further studies on CI are outlined.

The paper provides some valuable information on using different information tools and technologies for CI building. The results of this study may be useful for ICT specialists, as well as for the organizations that plan to build CI.
\end{abstract}

Keywords: Competitive Intelligence (CI), Business intelligence (BI), information tools and technologies, data exploration, data exploitation

\section{Introduction}

The source of organization's power has shifted from land, finance and capital to intangible resources (Herschel \& Jones, 2005;

Material published as part of this publication, either on-line or in print, is copyrighted by the Informing Science Institute. Permission to make digital or paper copy of part or all of these works for personal or classroom use is granted without fee provided that the copies are not made or distributed for profit or commercial advantage AND that copies 1) bear this notice in full and 2) give the full citation on the first page. It is permissible to abstract these works so long as credit is given. To copy in all other cases or to republish or to post on a server or to redistribute to lists requires specific permission and payment of a fee. Contact Publisher@InformingScience.org to request redistribution permission. McGonagle \& Vella, 2002; Moss \& Atre, 2003; Negash \& Gray, 2008). The organizations are governed by information, knowledge, intelligence and wisdom (Liautaud \& Hammond, 2002; Davenport \& Harris, 2007; Wixom \& Watson, 2010). The competitive advantage is based not only on products and finance, but also on intelligence, technology, software, education and culture. 
Resource-based View (RBV), a well-known theory of strategy argues that organizations with valuable, rare, inimitable and non-substitutable resources have the potential of achieving superior performance (Barney, 1995). In an extended approach of RBV resources implies intangible categories including organizational, human and networks (Ahn \& York, 2011). This knowledge-based resource approach of RBV encourages organizations to obtain, access, and maintain intangible endowments because these resources are the ways in which firms combine and transform tangible input resources and assets (Wiklundi \& Shephered, 2003). Furthermore, intangible resources are more causally ambiguous and less observable than tangible resources; therefore, it is not easy for competitors to duplicate. To provide sustainable competitive advantage, resources should be (Cosic, Shanks, \& Maynard, 2012): valuable (enable an organization to implement a value-creating strategy), rare (are in short supply), inimitable (cannot be perfectly duplicated by rivals), nonsubstitutable (cannot be countered by a competitor with a substitute).

Business Intelligence (BI) and Competitive Intelligence (CI), the significant research areas in the domain of management information systems, are well grounded in resource-based view theory. $\mathrm{BI}$ and $\mathrm{CI}$ are focused on the collecting, integrating, analyzing and sharing data that come from different, heterogonous, dispersed sources (Albescu, Pugna, \& Paraschiv, 2008; Baaras \& Kemper, 2008; Chung, Chen, \& Nunamaker, 2005; Venter \& Tustin, 2009). What's more, they do not focus exclusively on technology and applications, but also the on the business context and decision-making (Davenport \& Harris, 2007; Olszak, 2013). It is worth mentioning, that BI and CI seem to be recognized by many organizations as a valuable tool to reach strategic goals, increase profitability, improve customer satisfaction and ensure regulatory compliance (Howson, 2008; Olszak \& Ziemba, 2012; Weiss, 2002; Williams \& Williams, 2007; Wixom \& Watson, 2010). In this respect, study of BI and CI is highly necessary (Chen, Chiang \& Storey, 2012; Clavier, Lotriet \& Loggerenberger, 2012; Ishikawa \& Nakagawa, 2013). It enriches RBV theory providing new methods and techniques for better and effective management of intangible resources.

Last time the more attention is paid to CI (Teo \& Choo, 2001; Venter \& Tustin, 2009). CI is usually treated as a subset of BI, providing a balanced picture of the environment to the decision makers (Sauter, 2010). It is believed that CI is a vital tool for guaranteeing victory in a particular market competition (Karim, 2011; Schick, Frolick, \& Ariyachandra, 2011).

Although, the idea of CI has been explored for many years, unfortunately the investigations on different information tools and technologies for CI building are only partly addressed by any existing research. The studies are rather rare, fragmentary and do not describe in a comprehensive way the possibilities offered by different information tools for CI building.

The main purpose of this paper is to provide an overview of the issue of CI and to explore various information tools and technologies for CI building. This paper will answer the following question: What information tools and technologies should be used to build CI?

The structure of this paper is organized as follows. Firstly, the idea of CI is explained and the most important differences between BI and CI are highlighted. Next, some information tools and technologies for building CI are preceded. Finally, some guidelines and recommendations are provided in order to build CI in organizations. Some limitations of this research are indicated as well. What is more, further studies on CI were outlined. The results of this study may be useful for ICT specialists, as well as for the organizations that plan to build CI.

\section{Theoretical Background}

Organizations collect and analyze information for the different purposes. They may refer to (Ishikawa \& Nakagawa, 2013): (1) deepening and expanding of existing business, (2) risk management, (3) information control and security control and management, as well as (4) information 
manipulation. Until now, organizations usually have gathered and analyzed internal information in order to better understand their business processes and to improve decision-making on an operational and tactical level (Negash \& Gray, 2008). Recently, they have started to collect and explore the external information that comes from the organizational environment (Baaras \& Kemper, 2008; Olszak, 2012). This includes information about competitors, industries, governments and nations for management strategy, as well as information about background information (technology, politics, economy, society and culture), changing business environment and trends of suppliers of materials, exporting nations, competitors and overseas markets. Organizations believe that the above-mentioned information is as valuable for them (and sometimes even more) as information that comes from their own internal sources. Many authors emphasize that organizations that can understand their environment, their competitors and establish competitive management strategies will win in this rapidly globalization information society (Davenport \& Harris, 2007; Ishikawa \& Nakagawa, 2013). They predict that CI will revolutionize management tools and be more important for the success of any organization (Weiss, 2002).

The analysis of the literature allows to state that the term of "Competitive Intelligence" dates back to many years ago. Sawka (1996) defines CI as a knowledge and foreknowledge about the external operating environment. The author considers CI as a prelude to informed decisionmaking. He argues that intelligence can be viewed as any actionable information about a customer, market situation, regulator and competitor. The Society of Competitive Intelligence Professionals, an official US-based intelligence organization, defines Competitive Intelligence as "timely and fact-based data on which management may rely on decision-making and strategy development. It is carried out through industry analysis, which means understanding the players in a industry; competitive analysis, which means understanding the strengths and weaknesses of competitors; and benchmarking i.e. the analysis of individual business process of competitors" (Calof, 1997).

The development of different information tools, including data mining, data warehouse, OLAP (On-Line Analytical Processing) and dashboards, has resulted in the popularization of the "Competitive Intelligence" term (Olszak, 2012). Nowadays CI is considered as an important part of the contemporary organization. Styes (2010) states that CI is the collecting and analyzing of intelligence about the behaviors of the various market's actors in order to make certain decisions based on market trends. Ishikawa and Nakagawa (2013) consider that CI refers to the collecting, selecting and interpreting available information that reflects competitors' position, performance, capabilities and intentions.

Analyzing the nature of the CI is worth noting the differences between BI and CI. According to Albescu, Pugna, and Paraschiv (2008) BI is the activity of monitoring mostly the internal business processes, while $\mathrm{CI}$ is focused on the monitoring of external environment and uses public resources to locate and develop information on competition and competitors. CI is the natural exploit of the increasing availability of commercial databases world-wide, the on-line mass media and the development of cutting edge information technologies: BI and knowledge management. Also, Styl (2012) argues that BI cannot replace CI and vice versa. BI is the management of a company's internal data and processes that are well structured. This includes the Extract, Transform and Loading (ETL) of this data in a well-designed data warehouse in order to extract and present the data as intelligent information. BI may help any business make better decisions based on its own historic information and can therefore project possible future trends. In turn, the data that originates from external sources is usually semi-structured and unstructured. Thus, it seems that the tools used to collect, process and analyze data (known form typical BI systems) are inadequate and insufficient. This does not mean that the functions like: reporting, OLAP, simple data mining should be depreciated. They have still their strong position in analyzing many information sources. 
The main differences between BI and CI are presented in Table 1.

Table 1: The basic differences between BI and CI

\begin{tabular}{|c|c|c|}
\hline & Business Intelligence & Competitive Intelligence \\
\hline Purpose & $\begin{array}{l}\text { Analyzing mostly of the internal } \\
\text { business processes, improvement } \\
\text { operational and tactical decisions }\end{array}$ & $\begin{array}{l}\text { Monitoring, analyzing of external envi- } \\
\text { ronment - customers, suppliers, competi- } \\
\text { tors, increasing strategic decisions }\end{array}$ \\
\hline Scope & Organization & Environment of organization \\
\hline Content/data & $\begin{array}{l}\text { Well structured content, internal data } \\
\text { coming from data bases, ERP, trans- } \\
\text { action systems }\end{array}$ & $\begin{array}{l}\text { Semistructured, unstructured content, } \\
\text { external data coming from public, open } \\
\text { resources, Internet }\end{array}$ \\
\hline $\begin{array}{l}\text { Used tools, technolo- } \\
\text { gies }\end{array}$ & OLAP, data mining, data warehouse & $\begin{array}{l}\text { Advanced data mining, predictive model- } \\
\text { ing, web mining, text mining, agent } \\
\text { technology, exponential random graph } \\
\text { models, search based application, } \\
\text { dashboards, SOA }\end{array}$ \\
\hline
\end{tabular}

The process perspective is an essential aspect of CI. Karim (2011) reports that CI is a systematic process that allows for identifying competition's plans and intentions to obtain some advantage. This process involves collecting, processing, analyzing, and distributing to top management and other decision makers any information about an organizations' external environment. McGonagle and Vella (2002) describes CI as a formalized but developing process that is used by managers to evaluate the evolution of their industry and the capabilities and behavior of their competitors and those who might be their competitors in future. It is assumed that CI is the analytical process that transforms scattered information about competitors and customers into relevant, accurate and usable strategic knowledge on market evolution, business opportunities and threats (Teo \& Choo, 2001).

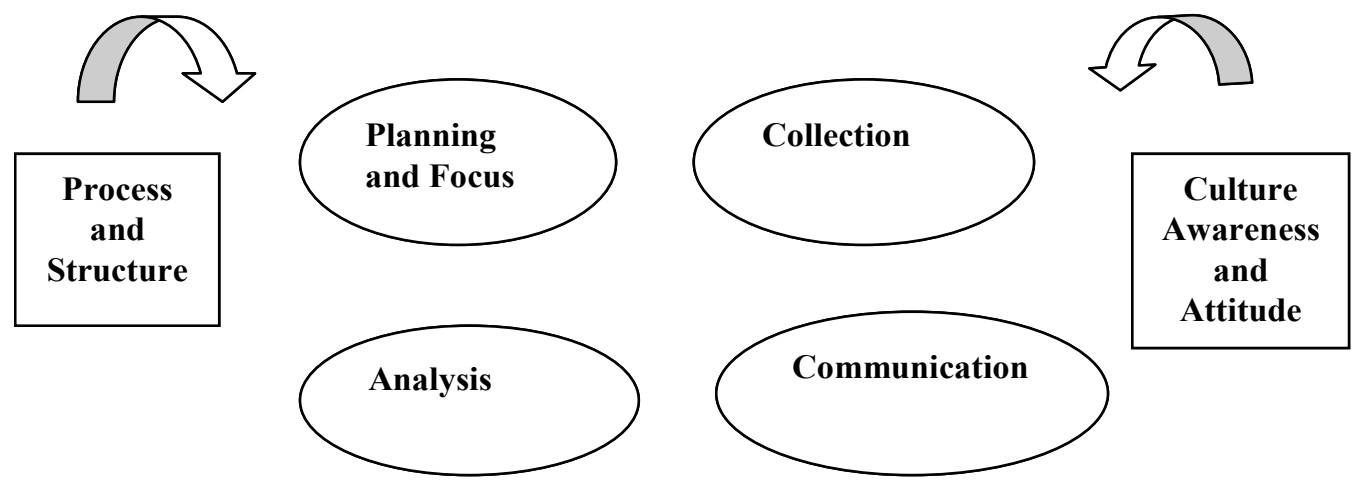

Figure 1: The Competitive Intelligence process (Source: Taib et al., 2008)

According to Taib et al. (2008), CI consists of the following processes (Figure 1):

- planning and focus, i.e. focusing on issues of highest importance to senior management;

- collection, i.e. the focused collection of information from a variety of sources internal or external to the company;

- analysis, i.e. converting information into "actionable intelligence" on which strategic and tactical decisions may be;

- communication, i.e. packaging and communicating the results of the CI process or project to those with the authority and responsibility to act on the findings;

- process and structure, i.e. those structures that ensure effective CI can be performed; 
- organizational awareness and culture, i.e. to ensure that $\mathrm{CI}$ is well executed and that all should participate, there must be the right competitive culture and information gathering.

In conclusion, it should be pointed that $\mathrm{BI}$ is aimed at the analysis of internal data and processes, while $\mathrm{CI}$ is focused on the monitoring of external environment. CI uses public resources to locate and develop information on competition and competitors.

\section{Methodology and Results}

In this study, the main sources of information were written documents (literature, reports) and own experiences with the work of different information tools, software programs. Many different information tools/technologies (the most important software providers, like: IBM, Microsoft, Oracle, SAS SAP) focusing on the data exploration, as well as on the data exploitation, have been investigated. I believe that organizations should develop two parallel activities in order to build CI. The former concerns the widely understood data exploration, whereas the latter, the data exploitation. Data exploration enables to overcome the bounder of actual knowledge of the organization and its capabilities. It may refer to new technical capabilities, market experiences and new relations with the environment. In turn, the data exploitation concerns the use of existing knowledge bases. It is limited to actual resources and refers to their detail analysis (Lavie, Stettner \& Tushman 2010).

Ten types of tools and technologies appropriate for building CI have been distinguished (Table 2). They include: (1) predictive modeling and data mining activities, (2) text mining, (3) web mining, (4) agent-based models, (5) exponential random graph models (ERGM), (6) search based application, (7) dashboards, (8) interactive visualization tools, (9) balance scorecard, (10) Service-Oriented Architecture (SOA). They have been analyzed from exploration and exploitation perspective. The exploration perspective refers to the possibility of overcoming the bounder of actual knowledge. While the exploitation perspective concerns the using of existing knowledge bases. The first six types of CI tools are focused on data exploration, while the others (7-10) on data exploitation. The synthesis analysis of these tools is presented below.

Table 2: Types of tools and technologies for building CI

\begin{tabular}{|l|l|}
\hline \multicolumn{1}{|c|}{ Data exploration perspective } & \multicolumn{1}{c|}{ Data exploitation perspective } \\
\hline 1. Predictive modeling and data mining activities & 7. Dashboards \\
\hline 2. Text mining & 8. Interactive visualization tools \\
\hline 3. Web mining & 9. Balance scorecard \\
\hline 4. Agent-based models & 10. Service-Oriented Architecture (SOA) \\
\hline 5. Exponential random graph models (ERGM & \\
\hline 6. Search based application & \\
\hline
\end{tabular}

\section{Category of Cl tools for Data Exploration}

Predictive modeling and advanced data mining activities constitute an interactive process aimed at the analysis of large databases, with the purpose of extracting information and knowledge that may prove accurate and potentially useful for knowledge workers engaged in decision making and problem solving (Vercellis, 2009). Data mining activities can be subdivided into two 
major investigation streams, according to the main purpose of the analysis: interpretation and prediction (Poul, Gautman, \& Balint, 2003). The purpose of interpretation is to identify regular patterns in the data and to express them through rules and criteria that can be easily understood by experts in the application domain. The purpose of prediction is to anticipate the value that a random variable will assume in the future or to estimate the likelihood of the future events. Different mathematical models and methods are used in such advanced data mining. The most important include: regression, time series, classification, association rules, and clustering (Han, Kamber \& Pei, 2011; Larose, 2005).

The purpose of regression models, also known as explanatory models, is to identify a functional relationship between the target variable and a subset of the remaining attributes contained in the dataset. Regression models serve to highlight and interpret the dependency of the target variable on other variables. They are used to predict the future value of the target attributes, based upon the functional relationship identified and the future value of the explanatory attributes (Tan, Steinbach, \& Kumar, 2005).

Time series model refers to the datasets in which the target attribute is time dependant. Its aim is to find any regular pattern of observations relative to the past, with the purpose of making predictions for future periods (Larose, 2005).

The purpose of classification model is to identify recurring relationships among the explanatory variables that describe the examples belonging to the same class. Such relationships are then translated into classification rules that are used to predict the class of examples for which only the values of the explanatory attributes are known.

Association rules - their aim is to select regular patterns and recurrences within a large set of transactions. They are fairly simple and intuitive and are frequently used to investigate sales transactions in market basket analysis, navigation paths within websites, as well as, fraud detection and purchases with a credit card (Vercellis, 2009).

The purpose of clustering is to find homogeneous groups of records called clusters. In some applications, the clusters generated may provide a meaningful interpretation of the phenomenon of interest. For example, grouping customers on their purchase behaviors may reveal the existence of a cluster corresponding to a market niche to which it might be appropriate to address specific marketing actions for promotional purpose (Han, Kamber, \& Pei, 2011).

Text and web mining are commonly used to process and analyze unstructured web contents. Text analytics is required and used because a significant portion of the unstructured content collected by an organization is in the textual format, from e-mail communication and corporate documents to web pages and social media content (Chen, Chiang, \& Storey, 2012). Text analytics is based on the knowledge originating from information retrieval and computational linguistics. In information retrieval, document representation and query processing are the foundations for developing the vector-space model, Boolean retrieval model, and the probabilistic retrieval model. While in computational linguistics, statistical natural language processing (NLP) techniques for lexical acquisition, word sense disambiguation, part-of -part tagging (POST) and probabilistic context-free grammars have become important for representing text. Text mining may refer to (1) Data processing: preprocessing of the data to the needed format; (2) Concept extraction: extraction of important concepts and terms through initial text analysis; (3) Narrative analysis: writing a narrative analysis to identify patterns and co-occurrences of identified concepts; (4) Automatic categorization: developing an automated solution; and (5) Ontology building: building ontology for future CI analysis.

Leveraging the power of big data and statistical NLP, text analytics techniques have been actively pursued in several emerging areas, including information extraction, topic models, question- 
answering $(\mathrm{Q} / \mathrm{A})$, event detection $(\mathrm{ED})$ and opinion mining $(\mathrm{OM})$. Information extraction aims to automatically extract specific kinds of structured information from documents. As a building block of information extraction, NER (named entity recognition) is a process that identifies atomic elements in text and classifies them into predefined categories. NER techniques have been successfully developed for news analysis and biomedical applications (Witten et al., 2011).

Question answering (Q/A) systems relies on techniques from NLP, informational retrieval, and human-computer interaction. Primarily designed to answer factual questions (who, what, when, and where kinds of questions), Q/A systems involve different techniques for question analysis, source retrieval, answer extraction, and answer presentation (Maybury, 2004). Event detection focuses on identifying information about events, such as type, time, place, participants and date of the event. Examples of a business event appearing in a newspaper could be a company establishing a new production facility or releasing a new product. Event detection process consists of three steps: event topic reasoning, event property extracting, and similarity comparison. The event topic reasoning step includes: representing the input text by a feature set pertaining to each event topic (e.g., when, who, where, what) and classifying the text into an appropriate event topic based on the event categorization patterns. Event property extraction refers to creating by extracting the event properties (e.g. participating company's names, dates, time, place of the event) based on event ontology. Event similarity comparison refers to the process of determining whether a new input document discusses a new or a previously known event. Opinion mining, also known as sentiment analysis (SA), refers to the computational techniques for extraction, classifying, understanding, and assessing the opinions expressed in various on line news sources, social media comments, and other user-generated content (Chen, Chiang \& Storey, 2012; Newman, 2010). It attempts to automatically measure human opinions from a text written in natural language.

In turn, web mining, the other set of methods and tools used to process and analyze unstructured web contents, based on XML, Internet protocol (HTTP, SMTP) APIs (application programming interface), enables developers to integrate diverse content from different web-enabled systems. A major component in web analytics is cloud computing, which includes applications, systems software, and hardware delivered as services over the Internet. Based on service-oriented architecture (SOA), server virtualization, and utility computing, cloud computing can be offered as software as a service (SaaS), infrastructure as a service (IaaS), or platform as a service (PaaS). The SaaS model means provision of certain software functionality. In model IaaS the infrastructure is delivered to customer. The PaaS model refers to an infrastructure and development environment for developing specific cloud applications. It is reported that there are four methods of providing cloud services: community cloud, public cloud, private cloud, and hybrid cloud (Veber, 2012).

Agent-based models. The agent is an entity that performs some actions in a particular environment and is aware of the emerging changes. Moreover, it can react to such changes (Olszak \& Bartuś, 2013; Poole \& Mackworth, 2010). The agent has a set of goals, certain capabilities to perform actions, and some knowledge (or beliefs) about its environment (Wang \& Wang, 2005). The agent model as "a solution-oriented ensemble of capabilities including natural language processing, autonomous reasoning, proactive computing, discourse modeling, knowledge representation, action-oriented semantics, multimodal interaction, environmental awareness, self awareness, and distributed architectures" (Thomsen, 2002). It involves software entities that carry out some set of operations on behalf of a user or another program, with some degree of independence or autonomy, and in so doing, employ some knowledge or representation of user's goals and desires (IBM, 2012).

Exponential random graph models (ERGMs) are a family of statistical models for analyzing data about social and other networks (Robins et al., 2007). To support statistical inference on the process influencing the formation of network structure, ERGMs consider the set of all possible 
alternative networks weighted on their similarity to observed networks. Such tools like UCINet and Pajek have been developed and are widely used for large-scale network analysis and visualization (Borgatti et al., 2002; Chen, Chiang, \& Storey, 2012). In addition, lightweight programming models of the current web services (HTML, XML, CSS, Ajax, Flash, J2J) and the maturing mobile development platforms such as Android and IOS have contributed to the rapid development of mobile web services (HTML5, Mobile Ajax, Mobile Flash, J2ME) in various social networks.

Search based application is a category of application that enables users to find information from any source and in any format with a search-based application. The user can enter anything he knows about the customer or product, and the search engine will try to find those customers or products that resemble the keywords entered by the user. According to Capgemini (2013), there are different reasons for using search engines: (1) they are very flexible in handling any format and type of information, be it structured, unstructured or external; (2) they are able to cope with continuously evolving data structures. Indexing both existing and new data does not require extensive data-modeling; (3) search engines enable content-driven dimensional navigation. At each step of navigation search engines propose different possibilities to filter results according to the content of the datasets that are being indexed and analyzed in near real-time; (4) search engines, unlike solutions based on RDBMS, are able to analyze data without the need to know the various data types; (5) end users are now quite familiar with the "Google" interface. As a consequence, they are much more independent from IT departments if they can access decision support data through a search engine; (6) when external and unstructured data is needed to support decision making, traditional data warehouse architectures are limited and search engines can help to fill the gap; (7) search engines include functionality to automatically generate categories and clusters, hence improving the contextualization and meaning of data; (8) search engines can work with existing information systems (e.g. data warehouses, data marts, production systems, etc.) and provide a federated view of data without compromising on performance.

\section{Category of $\mathrm{Cl}$ tools for Data Exploitation}

Dashboards are the tools for visualization of important business data presented in the form of graphic indicators, charts and tables (Kirtland, 2003; Vasilliu, 2009). Sometimes dashboards are treated as an easy to read, often single page, real-time user interface, showing a graphical presentation of the current status (snapshot) and historical trends of an organization's key performance indicators to enable instantaneous and informed decisions to be made at a glance. They extend static reporting on analytical elements. They aggregate and sensitize data using such methodologies like: BSC, SixSigma, Economic Value-Added. So, they enable managers to better assess operational and strategic information and better understand business.

Interactive visualization tools enable decision makers to dynamically explore ideas, investigate patterns, uncover hidden facts and share those insights across the enterprise for better decision making. An extensive suite of customizable graphical presentation options present information and insights not easily detected in tabular formats. The most important features of interactive visualization include the following (SAS, 2013): (1) providing dynamic business visualization for interactive data exploration, visual queries and more; (2) seeing relationships that are not easily discovered in tabular formats; (3) making complex interrelationships visible in an easy-tounderstand picture; (4) creating data movies using engaging, Adobe Flash-based interactivity; (5) providing highly interactive business graphics, including animated bubble plots, 3-D scatter plots, trellis plots, summary charts and needle charts; (6) generating static or dynamic interactive (Java or ActiveX) charts and graphs that can be used in third-party applications; (7) visually querying and filtering data for interactive tabulation with the ability to rearrange data at will; (8) providing 
visual analytics, including interactive simulations and optimization, and state-of-the-art time series modeling.

Balanced scorecard (BSC) is a strategy performance management tool - a semi-standard structured report, supported by design methods and automation tools, that can be used by managers to keep track of the execution of activities by the staff within their control and to monitor the consequences arising from these actions. The BSC concept introduced by Kaplan and Norton (1996) is now seen as a critical foundation in a holistic strategy execution process that, besides helping or-

ganizations articulate strategy in actionable terms, provides a road map for strategy execution, for mobilizing and aligning executives and employees, and making strategy a continual process.

Service-Oriented Architecture (SOA) enables organizations to use different cloud services. SOA is a computing paradigm that utilizes services as fundamental elements for developing systems (Microsoft, 2006). A service could be considered as a "set of software operations and components built in a way that allows them to be easily, flexibly, and dynamically integrated to cover both business and IT needs" (Riad \& Hassan, 2008). It is worth indicating that the history of SOA goes back to a concept known as software-as-a-service (SaaS) which first appeared with the Application Service Provider (ASP) software model. Unfortunately, ASP model is burdened with several inherent limitations such as, e.g. inability to provide complete customizable applications. These limitations allow the SOA paradigm to emerge to offer delivery of complex business processes in form of network addressable components known as services that could be accessed and reused everywhere by everyone on condition that access permissions are granted to requestors (Papazoglou, 2003).

\section{Discussion}

The world of data has changed in the last years. Also, the way of exploration of data and building data models has been changed. Specially, the amount of information from new sources like the Internet and social media has been increasing. Bigger and better data resources provide organizations with a more panoramic and detailed look at the business environment. However, in order to use and monitor the data from the environment, the organizations should (1) seek creative ways and tools for the exploitation and exploration of the resources of data, and the acquisition of new sources, (2) build data models to enable prediction of business performance and optimization, and (3) transform the company's ability.

The organizations need to think creatively about the potential of new, external data sources. Managers do not always know how such sources can be used in making decisions. The initiatives in this field should be disseminated not only by senior managers, but also by the operational staff who are responsible for monitoring customers' opinions etc. All employees should be sensitive to innovative methods of information collection and data management. Inherited from the previous years IT structure may hinder the use of new methods of data collection, storage and analysis. Many older information systems were built so as to provide data in batches. They cannot, therefore, provide a steady stream of information needed by making decisions in real time. Addressing these, time, education and transformation of the IT structures are all required. Cloud computing is a solution that allows for increasing computing power needed to process vast amounts of information.

The starting point in CI building should be an indication of any business opportunity and determination of how a specific tool can, for example, improve the performance. One of the methods that does not guarantee satisfactory results is data mining or web mining. Projected data models have to be aligned to the processes of company and its decision-making practices.

The capabilities of organizations do not go hand in hand with the possibilities offered by new information tools. Most organizations need to raise their "analytical erudition." This requires con- 
ducting a number of training courses, transformation of the organizational culture and the creation of appropriate incentive to reinforce the desired behavior. The fact is that the existing (presented) CI tools are not aimed at line workers, but rather at experts in statistics and software developers.

I believe that organizations should simultaneously develop two activities in order to build CI (Table 3). The former concerns the widely understood data exploration, the latter, data exploitation. Data exploration enables organization to overcome the bounder of actual knowledge and its capabilities. This may refer to new technical capabilities, market experiences and new relations with the environment. Also, the exploration is a conscious searching of new knowledge sources, enriching of existing resources, adoption of new behavioral orientations and acquisition of new competencies. It can be achieved through advances data mining, text mining, web mining, intelligent agents, ERGM, and search based application.

Table 3: Completive Intelligence tools from data exploration and exploitation perspective

\begin{tabular}{|c|c|c|c|}
\hline Tools & Application domains & Strength & Weakness \\
\hline \multicolumn{4}{|c|}{ CI tools for data exploration } \\
\hline $\begin{array}{l}\text { 1. Predictive model- } \\
\text { ing and data mining } \\
\text { activities }\end{array}$ & $\begin{array}{l}\text { Interpretation and predic- } \\
\text { tion }\end{array}$ & $\begin{array}{l}\text { Analysis of large data- } \\
\text { bases, discovering new } \\
\text { correlations }\end{array}$ & $\begin{array}{l}\text { Needed knowledge on } \\
\text { different mathematical } \\
\text { methods and models, } \\
\text { dedicated to small group } \\
\text { of users }\end{array}$ \\
\hline 2. Text mining & $\begin{array}{l}\text { E-mail communication, } \\
\text { corporate documents, web } \\
\text { pages and social media } \\
\text { content, opinion mining }\end{array}$ & $\begin{array}{l}\text { Processing and analyz- } \\
\text { ing of unstructured } \\
\text { web contents }\end{array}$ & $\begin{array}{l}\text { Complex implementa- } \\
\text { tion of the text mining } \\
\text { techniques and some } \\
\text { difficulties in interpreta- } \\
\text { tion of obtained results }\end{array}$ \\
\hline 3. Web mining & $\begin{array}{l}\text { Cloud computing, SOA, } \\
\text { social media, opinion min- } \\
\text { ing }\end{array}$ & $\begin{array}{l}\text { Integrating diverse } \\
\text { content from different } \\
\text { web-enabled systems }\end{array}$ & $\begin{array}{l}\text { Complex implementa- } \\
\text { tion of the web mining } \\
\text { techniques and some } \\
\text { difficulties in interpreta- } \\
\text { tion of obtained results }\end{array}$ \\
\hline $\begin{array}{l}\text { 4. Agent-based } \\
\text { models }\end{array}$ & $\begin{array}{l}\text { Natural language process- } \\
\text { ing, autonomous reasoning, } \\
\text { proactive computing, dis- } \\
\text { course modeling, knowl- } \\
\text { edge representation, action- } \\
\text { oriented semantics, multi- } \\
\text { modal interaction, envi- } \\
\text { ronmental awareness }\end{array}$ & $\begin{array}{l}\text { Reacting to changes, } \\
\text { carrying out some set } \\
\text { of operations on behalf } \\
\text { of a user or another } \\
\text { program, with some } \\
\text { degree of independ- } \\
\text { ence or autonomy, } \\
\text { reduction of work re- } \\
\text { sources (time, special- } \\
\text { ists) }\end{array}$ & $\begin{array}{l}\text { Complex process of } \\
\text { development and con- } \\
\text { figuration of the agent } \\
\text { system }\end{array}$ \\
\hline $\begin{array}{l}\text { 5. Exponential ran- } \\
\text { dom graph models } \\
(\mathrm{ERGM})\end{array}$ & $\begin{array}{l}\text { Large-scale network analy- } \\
\text { sis and visualization, mo- } \\
\text { bile web services, various } \\
\text { social networks }\end{array}$ & $\begin{array}{l}\text { Using of mobile plat- } \\
\text { forms such as Android } \\
\text { and IOS }\end{array}$ & $\begin{array}{l}\text { Needed knowledge on } \\
\text { statistical models }\end{array}$ \\
\hline $\begin{array}{l}\text { 6. Search based } \\
\text { application }\end{array}$ & $\begin{array}{l}\text { Find information from any } \\
\text { source and in any format }\end{array}$ & $\begin{array}{l}\text { Independent from IT } \\
\text { departments, } \\
\text { can work with existing } \\
\text { information systems }\end{array}$ & $\begin{array}{l}\text { Complex process of } \\
\text { development of search } \\
\text { based application }\end{array}$ \\
\hline
\end{tabular}




\begin{tabular}{|l|l|l|l|}
\hline \multicolumn{4}{|c|}{ CI tools for data exploitation } \\
\hline 7. Dashboards & $\begin{array}{l}\text { Visualization of data, real- } \\
\text { time user interface }\end{array}$ & $\begin{array}{l}\text { Using different meth- } \\
\text { odologies: BSC, Six- } \\
\text { Sigma, Economic } \\
\text { Value-Added, dedi- } \\
\text { cated to managers }\end{array}$ & $\begin{array}{l}\text { Presentation of current } \\
\text { status, indicators and } \\
\text { historical trends in or- } \\
\text { ganization }\end{array}$ \\
\hline $\begin{array}{l}\text { 8. Interactive visu- } \\
\text { alization tools }\end{array}$ & $\begin{array}{l}\text { Dynamic business visuali- } \\
\text { zation, interactive simula- } \\
\text { tions and optimization }\end{array}$ & $\begin{array}{l}\text { Providing highly inter- } \\
\text { active business graph- } \\
\text { ics and analytics }\end{array}$ & $\begin{array}{l}\text { Needed high-quality } \\
\text { hardware and software } \\
\text { (Adobe Flash, Java, } \\
\text { ActiveX) }\end{array}$ \\
\hline $\begin{array}{l}\text { 9. Balance score- } \\
\text { card }\end{array}$ & $\begin{array}{l}\text { Strategy performance man- } \\
\text { agement }\end{array}$ & $\begin{array}{l}\text { Holistic strategy exe- } \\
\text { cution process }\end{array}$ & $\begin{array}{l}\text { Needed extensive organ- } \\
\text { izational knowledge }\end{array}$ \\
\hline $\begin{array}{l}\text { 10. Service- } \\
\text { Oriented Architec- } \\
\text { ture (SOA) }\end{array}$ & Cloud services & $\begin{array}{l}\text { Flexibly and dynamic } \\
\text { integration business } \\
\text { and IT needs }\end{array}$ & $\begin{array}{l}\text { Needed high-quality IT } \\
\text { infrastructure and ser- } \\
\text { vices }\end{array}$ \\
\hline
\end{tabular}

Data exploitation concerns the using of existing knowledge bases. It is limited to actual resources and refers to their detail analysis. It includes balanced scorecards, dashboards, visualizations, and SOA.

Data exploration has a stronger influence on the long-term decisions. It enables organization to increase their market shares or sales. Data exploitation refers to the short-term activities measured e.g. income level and the size of the property.

I believe that adequate linking activities concerning exploration and exploitation of the knowledge are useful solution for organization. This results from the rapid obsolescence of knowledge, shortening life cycle of many products and services. Additionally, it should be highlighted that the knowledge - new for one organization, may be known and used for another. Consequently, in one organization knowledge may be scope of the exploration, and in another the scope of the exploitation. It is difficult not to agree with the statement that contemporary organization stands before an appointment of a compromise between the exploration and data exploitation. The organizations that engage exclusively in the data exploitation may face a "trap alone". In turn, organizations that focus solely on exploration can incur significant costs associated with experimentation, innovation and knowledge acquisition. Therefore, it is important for the survival and success of the organization to maintain some balance between these activities.

\section{Conclusions and Recommendations}

This paper has discussed possibilities of different tools for CI building. It has described and distinguished two groups of CI tools - from data exploration and data exploitation perspectives. The first group of CI tools includes: advanced data mining, web mining, text mining, agent technology, ERGMs and search based applications. They help the organization to overcome the bounder of actual knowledge and its capabilities. They are focused on searching of new knowledge sources, enriching of existing resources, adoption of new behavioral orientations and acquisition of new competencies. They are predisposed to support the long term decisions, prediction and optimalization. The second group of CI tools includes: dashboards, interactive visualization tools, balance scorecard and SOA. These tools involve using of existing knowledge bases. These CI tools are also limited to actual resources and refer to historical analysis. They help to integrate business and IT needs. 
Information Tools and Technologies for Competitive Intelligence Building

The optimal balance of using such CI tools is required. The successful data exploitation and data exploration balancing provides an opportunity for effective functioning of the organization. Such a balanced coexistence of exploration and exploitation of knowledge meets the challenges faced by today's organizations. The organizations should search for effective CI tools both to discover new knowledge as well to exploit the existing knowledge.

\section{Limitations and Directions for Future Research}

This study suffers from some limitations. Firstly, the detailed, empirical tests on information tools for CI building should be conducted. Second, it should be investigated how CI tools work together with traditional BI tools (like: data base systems, data warehouse, OLAP) and others systems (ERP, CRM, SCM) in order to develop a holistic information repository for the organization. Third, in-depth interviews with ICT specialists and mangers should be conducted to obtain more information on users preferences and requirements for CI building

Future research might take some of the following directions. First, it would be valuable to build holistic approach for CI, including: planning, implementation, and control. Second, further research might explore the detailed paths of CI building. Lastly, further empirical investigations and precise validations are invited to explore the associations between CI, capabilities and strategic orientations of the organizations.

\section{Acknowledgment}

This paper has been supported by a grant: "Methodology for Computer Supported Organizational Creativity” from National Science Centre in Poland, 2013/09B/HS4/00473.

\section{References}

Ahn, M. J., \& York, A. S. (2011). Resource-based and institution-based approaches to biotechnology industry development in Malaysia. Asia Pacific Journal of Management, 28(2), 257-275.

Albescu, F., Pugna I., \& Paraschiv, D. (2008). Business intelligence \& knowledge management - Technological support for strategic management in the knowledge based economy. Revista Informatica Economică, 4(48), 5-12.

Baaras, H., \& Kemper, H. G. (2008). Management support with structured and unstructured data - An integrated business intelligence framework. Information Systems Management, 25(2), 132-148.

Barney, J. (1995). Looking inside for competitive advantage. Academy of Management Executive, 9, 49-61.

Borgatti, S. P., Everet, M. G., \& Freeman, L. C. (2002). UCInet for Widows: Software for social network analysis. Harvard. MA: Analytic Technologies.

Calof, J. L. (1997). For king and country... and company. Business Quarterly, 61(1), 32-39.

Capgemini. (2013). Consulting. Technology. Outsourcing. Retrieved September 2013 from http://www.capgemini.com/sites/default/files/resource/pdf/Search-Based BI.pdf

Chen, H., Chiang, R. H. L, \& Storey, V. C. (2012). Business Intelligence and analytics: From big data to big impact. MIS Quarterly, 36(4), 1-24.

Chung, W., Chen, H., \& Nunamaker, J. F. (2005). A visual framework for knowledge discovery on the web: An empirical study of business intelligence exploration. Journal of Management Information Systems, 21(4), 57-84.

Clavier, P. R., Lotriet, H., \& Loggerenberger, J. (2012). Business intelligence challenges in the context of goods-and service-domain logic. Proceedings of $45^{\text {th }}$ Hawaii International Conference on System Science, IEEE Computer Society, 4138-4147. 
Cosic, R., Shanks, G., \& Maynard, S. (2012). Towards a business analytics capability maturity model. $23^{\text {rd }}$ Australasian Conference on Information Systems, Geelong.

Davenport ,T. H., \& Harris, J. G. (2007). Competing on analytics. The new science on winning. Boston, Massachusetts: Harvard Business School Press.

Han, J., Kamber, M., \& Pei, J. (2011). Data mining. Concept and techniques. New York: Morgan Kaufmann.

Herschel, R. T., \& Jones, N. E. (2005). Knowledge management and business intelligence: The importance of integration. Journal of Knowledge Management, 9(4), 45-54.

Howson, C. (2008). Successful business intelligence: Secrets to making BI a killer application. New York: McGraw-Hill.

Kaplan, R., \& Norton, D. (1996). The balances scorecard. Boston, Massachusetts: Harvard Business Press.

Karim, A. J. (2011). The value of competitive business intelligence system (CBIS) to stimulate competitiveness in global market. International Journal of Business and Social Science, Special Issue, 2(19), 196-203.

Kirtland, A. (2003). Executive dashboards. Retrieved February 2006 from http://www.boxesandarrows.com/archives/executive dashboards.php

Larose, D. T. (2005). Discovering knowledge in data. An introduction to data mining. New York: John Wiley \& Sons.

Lavie, D., Stettner, U., \& Tushman, M. L. (2010). Exploration and exploitation within and across organizations. The Academy of Management Annals, 4(1), 109-155.

Liautaud, B., \& Hammond, M. (2002). E-business intelligence. Turning information into knowledge into profit. New York: McGraw-Hill.

McGonagle, J. J., \& Vella, C. M. (2002). Bottom line competitive intelligence. Westport, CT: Quorum Books.

Maybury, M.T. (2004). New direction in question answering. Cambridge: The MIT Press.

Microsoft. (2006). The future of information technology: Growing the talent critical for innovation. Microsoft White Paper. Retrieved July 2006 from http://research.microsoft.com/workshops/FS2006/papers/TheFutureofInformationTechnology.pdf

Moss, L., \& Atre, S. (2003). Business intelligence roadmap: The complete lifecycle for decision-support applications. Boston: Addison-Wesley.

Negash, S., \& Gray, P. (2008). Business intelligence. In F. Burstein \& C. W. Holsapple (Eds.), Decision support systems (pp. 175-193). Berlin: Springer.

Newman, M. E. J. (2010). Networks. An introduction. Oxford: Oxford University Press.

Olszak, C. M. (2012). Competing with business intelligence. In M. Tvrdikova, J. Minster, \& P. Rozenhal (Eds.), IT for practice (pp. 98-108). Ostrava: VSB-TU Economicka Faculta.

Olszak, C. M. (2013). The business intelligence-based organization - New chances and possibilities. International Conference on Management, Leadership and Governance. Bangkok University, Thailand, 241-249.

Olszak, C. M., \& Bartuś, T. (2013). Multi-agent framework for social customer relationship management systems. Issues in Informing Science and Information Technology, 10, 367-387. Retrieved from http://iisit.org/Vol10/IISITv10p367-387Olszak0055.pdf

Olszak C. M., \& Ziemba, E. (2012). Critical success factors for implementing business intelligence systems in small and medium enterprises on the example of Upper Silesia, Poland. Interdisciplinary Journal of Information, Knowledge, and Management, 7, 129-150. Retrieved from http://www.ijikm.org/Volume7/IJIKMv7p129-150Olszak634.pdf 
Information Tools and Technologies for Competitive Intelligence Building

Papazoglou, M.P. (2003). Service-oriented computing: concepts, Characteristics and directions. Proceeding of the Fourth International Conference on Web Information Systems Engineering (WISE'03).

Poole, D., \& Mackworth, A. (2010). Artificial intelligence: Foundations of computational agent. Cambridge: University Press.

Poul, S., Gautman, N., \& Balint, R. (2003). Preparing and data mining with Microsoft SQL Server 2000 and Analysis Services. New York: Addison-Wesley.

Riad, A. M., \& Hassan, Q. F. (2008). Service-oriented architecture - A new alternative to traditional integration methods in B2B applications. Journal of Convergence Information Technologies (JCIT), March, Korea.

Robins, G., Pattison, P., Kalish, Y., \& Lusher, D. (2007). An introduction to exponential random graph (p*) models for social networks. Social Networks, 29(2), 173-191.

SAS (2013). Retrieved September 202013 from https://www.sas.com/technologies/bi/visualization

Sauter, V. L. (2010). Decision support systems for business intelligence. New Jersey: Wiley.

Sawka, K. A. (1996). Demystifying competitive intelligence. Management Review, 85(10), 47-51.

Schick, A., Frolick, M., \& Ariyachandra, T. (2011). Competing with BI and analytics at monster worldwide. Proceedings of $44^{\text {th }}$ Hawaii International Conference on System Sciences, Hawaii.

Steyl, J. (2012). Knowledge management - BI vs. CI. Retrieved August 2012 from http://it.toolbox.com/blogs/bi-ci/business-intelligence-vs-competitive-intelligence-32441

Taib, K. M., Mat, Y. S. F., Ahmad, A. R., \& Mansor, A. N. (2008). Knowledge management and competitive intelligence: A synergy for organizational competitiveness in the k-economy. Communications of the IBIMA, 6.

Tan, P. N., Steinbach, M., \& Kumar, V. (2005). Introduction to data mining. New York: Addison-Wesley.

Teo, T. S. H., \& Choo, W. Y. (2001). Assessing the impact of using the Internet for competitive intelligence. Information and Management, 39(1), 67-83.

Thomsen, E. (2002). Agents uncovered. Intelligent Enterprise, 5(15), 45.

Vasiliu, A. (2009). Dashboards and scorecards: Linking management reporting to execution. Retrieved February 2009 from http://dssresources.com/papers/features/vasiliu/vasiliu04302006.html

Veber, J. (2012). Operational-economic aspects of cloud computing. In M. Tvrdikova, J. Minster, \& P. Rozenhal (Eds.), IT for practice (pp. 178-186). Ostrava: VSB-TU Economicka Faculta.

Venter, P., \& Tustin, D. (2009). The availability and use of competitive and business intelligence in South African business organizations. South African Business Review, 13(2), 88-115.

Vercellis, C. (2009). Business intelligence. Chichester: Wiley.

Weiss, A. (2002). A brief guide to competitive intelligence. Business Information Review, 19(2).

Wiklundi, J., \& Shepherd, D. (2003). Knowledge-based resources, entrepreneurial orientation, and the performance of small and medium-sized businesses. Strategic Management Journal, 24, 1307-1314.

Williams, S., \& Williams, N. (2007). The profit impact of business intelligence. Morgan Kaufmann, San Francisco.

Witten, I. H., Frank, E., \& Hall, M. (2011). Data mining: Practical machine learning tools and techniques. San Francisco: Morgan Kaufmann.

Wixom, B. H., \& Watson, H. J. (2010). The BI-based organization. International Journal of Business Intelligence Research, 1, 13-28. 


\section{Biography}

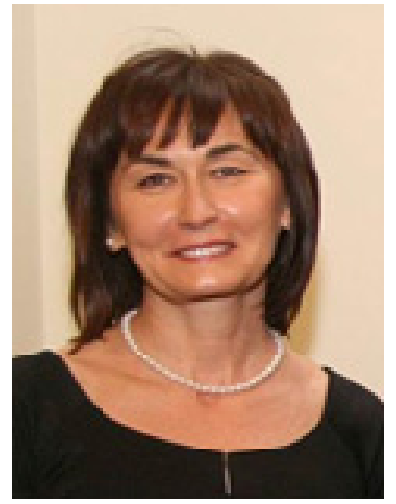

Prof. Celina M. Olszak, Ph.D.,D.Sc a head of the Department of Business Informatics, Dean for Research at the Katowice University of Economics, Poland. DAAD and Swiss Government scholarship holder. The author of 10 books and over 150 academic journal articles. Her research and teaching focus on decision support systems, business intelligence, management information systems and information society. She is a member of the Polish Academy of Sciences and Informing Science Institute in California, USA. 